\title{
UMA ABORDAGEM INTERACIONAL DOS SABERES E DAS CULTURAS PROFISSIONAIS ${ }^{12}$
}

\author{
Telmo H. Caria ${ }^{3}$ \\ Marise Ramos ${ }^{4}$
}

\begin{abstract}
Resumo
O artigo aborda o conceito de saber profissional no âmbito das Ciências Sociais vinculado com ao tema culturas profissionais, considerando contribuições da microssociologia, vindas da fenomenologia social e do interacionismo simbólico, em diálogo interdisciplinar com as Ciências Cognitivas e com o pensamento histórico-dialético em alguns aspectos, visando a contribuir para estudos sobre o trabalho profissional em interação social. Conclui destacando a importância de investigações empíricas sobre os elementos que interconectam tais componentes interacionais no interior do grupo profissional e sobre os efeitos das interações multiculturais na reflexividade interna desse mesmo grupo.
\end{abstract}

Palavras-chave: saber profissional, cultura profissional, microssociologia, sociocognição

\begin{abstract}
The article discusses the concept of professional knowledge in the field of Social Sciences linked with the theme professional cultures, considering contributions from microsociology (social phenomenology and symbolic interactionism) in interdisciplinary dialogue with the Cognitive Sciences and with historical-dialectical thinking in some aspects, aiming to contribute to studies of professional work in interaction. Concludes by highlighting the importance of empirical research about interconnect components such interactional within the professional group and the effects of multicultural interactions in professional reflexivity.
\end{abstract}

Keywords: professional knowledge, professional culture, microsociology, social cognition

\footnotetext{
1 DOI: https://doi.org/10.22409/tn.16i30.p10085

${ }^{2} \mathrm{O}$ conteúdo deste artigo é produto de estudos e pesquisas do primeiro autor, além de diálogos com a segunda no estágio pós-doutoral realizado na UTAD/Portugal, em 2012, ao identificar contribuição desses estudos para se compreender aspectos virtuosos da abordagem das competências que foram apropriadas pelo pensamento neoliberal, como as implicações subjetivas e interacionais dos trabalhadores no desenvolvimento de seus saberes e no enfrentamento das situações concretas de trabalho.

${ }^{3}$ Doutor em Sociologia da Educação - Universidade de Trás-os-Montes e Alto Douro (UTAD), Portugal. Docente do Departamento de Economia e Sociologia da Universidade de Trás-osMontes e Alto Douro e do Centro de Investigação e Intervenção Educativas da Faculdade de Psicologia e de Ciências da Educação da Universidade do Porto, Portugal. tcaria@utad.pt ${ }^{4}$ Doutora em Educação pela Universidade Federal Fluminense (2001). Docente no Programa de Pós-Graduação em Políticas Públicas e Formação Humana da Universidade do Estado do Rio de Janeiro e pesquisadora na Escola Politécnica de Saúde Joaquim Venâncio, da Fundação Oswaldo Cruz.mramos@fiocruz.br
} 


\section{Introdução}

No âmbito da sociologia do conhecimento, identificamos movimentos teóricos e um crescente interesse analítico por conexões entre conceitos e senso comum nas atividades e interações sociais práticas com o conhecimento, inspiradas na fenomenologia social, o que significou um avanço em relação às análises histórico-discursivas dos enunciados das ideias e das doutrinas políticoideológicas e uma focalização no uso prático do conhecimento (COUTER, 1989; DUBOIS, 2001; PHARO et al., 2003). Mesmo assim, a exemplo das correntes que enfatizam as aprendizagens a partir dos processos de recontextualização do conhecimento (BERNSTEIN, 1990, 1996; EVANS et. al., 2011), nessa renovada abordagem, o conhecimento conceitual, disponível, teórica e discursivamente, é o que tem se mantido central (CARIA, 2015).

Esta abordagem revela-se insuficiente para explicar a mobilização de conhecimento numa perspectiva horizontal, que articule práticas e significações em contexto de interação social e profissional, pois o conceito de recontextualização pensa a mobilização do conhecimento a partir de relações sociais que sobrevalorizam quem oferece e quem transmite (as instituições de educação formal, os educadores e os formadores) o conhecimento e não a partir da ação social de quem procura e de quem aprende (de quem usa conhecimento) na prática social (BRASSAC, 2007; CARIA, 2007; SAWCHUK, 2011). A recontextualização, assim, enfatiza a dependência da reflexividade social da reprodução dos poderes desiguais sobre o conhecimento abstrato e, tal como todas as abordagens estruturais e institucionais do social, salienta a determinação da escala macro de análise sobre as atividades práticas e ação social em contexto.

Esta constatação justifica a influência da fenomenologia social na elaboração teórico-metodológica dos saberes profissionais. Primeiramente, cabe explicar tratar-se de um estudo sobre as ações sociais de grupos numa dinâmica cotidiana, constituindo-se, assim, um objeto da microssociologia com inspiração compreensiva. Isto por considerar que a apreensão das formas de uso do conhecimento pelos profissionais em interação contribui para a compreensão de dinâmicas da sociedade. A fenomenologia, por sua vez, nos ajuda a colocar em questão análises sociais que tomam os conhecimentos abstratos como verdades 
independentes da prática social. Assim, a teorização que tomará corpo ao longo deste texto orienta investigações ao nível micro social, isto é, das interações.

Talvez Edmund Husserl tenha se atentado mais para este plano do que Karl Marx. Afinal, como afirma Paci (1968), Husserl não se interessou por Marx e na realidade o campo dos problemas do marxismo era estranho a suas investigações. Ele explica que em Husserl a psicologia é para a fenomenologia uma espécie de pedra de toque, uma "ciência das decisões" (PACl, 1968, p. 233, grifado no original), faltando-lhe o problema da relação entre a esfera das necessidades e das satisfações e sua estrutura condicionante.

Em seu estudo sobre Fenomenologia e Marxismo, o referido autor procura "instituir uma relação de recíproca integração e fecundação entre Marx e Husserl" (BOBBIO, 2006, p. 250): "se colocamos o marxismo em relação com a problemática fenomenológica, devemos esperar que se nos revele um marxismo crítico e uma possível nova leitura dos textos marxistas". (PACl, 1968, p. 233)

Não teríamos pretensão de tal monta quando sinalizamos as contribuições da fenomenologia para o presente estudo, em um diálogo interdisciplinar que inclui o pensamento histórico-dialético. Mas não deixa de nos interessar a proposição do filósofo italiano, ao discutir natureza e história na referida obra, sobre a presença das leis engelianas da dialética na análise fenomenológica de grupos, classes e comunidades. Na análise fenomenológica, segundo ele, modalidades dialéticas como as apresentadas por Engels - compenetração dos opostos, conversão da quantidade em qualidade e vice-versa, negação da negação - deveriam necessariamente ultrapassar a subjetividade entendida como ponto de partida ou como presença vivente e operante: "a subjetividade, já se viu, é também intersubjetividade que se determina em grupos sociais viventes". (PACl, 1968, p. 234) Este seria um ponto de diálogo entre a fenomenologia e o materialismo histórico-dialético neste estudo, ou seja, o foco na intersubjetividade que se processa no mundo real.

Uma pretensão para além desta, implicaria tematizar criticamente uma tentativa de integração dessas duas filosofias, tal como fez Bobbio (2006, p. 255), o que foge ao escopo deste texto. Mesmo assim, concordamos com o autor que $o$ marxismo é uma metodologia da história e a fenomenologia não tem a mesma abrangência. A alienação, questão comum a ambas, é abordada por eles 
distintamente; para o primeiro, é determinada pela ciência, para o segundo, pela economia. Por consequência, enquanto em Husserl a crítica das ciências e a descoberta do mundo-da-vida como esfera pré-categorial permitiria a volta ao sujeito e a sua libertação da objetividade que o subsume, Marx encontra a objetividade na crítica da economia política ao desvelar a falsificação das relações humanas pelo caráter abstrato desta ciência e pelas "mistificações subjetivas".

Essas, porém, são questões filosóficas. Colocado no plano sociológico, nosso objeto de estudo - os saberes profissionais - são considerados no mundo do cotidiano da intersubjetividade. Sendo assim, reconhecemos sua delimitação à perspectiva fenomenológica e, em convergência com Karel Kosik (1976, p. 11), seriam manifestações da pseudoconcreticidade: "o complexo dos fenômenos que povoam o ambiente cotidiano e a atmosfera comum da vida humana, que, com a regularidade, imediatismo e evidência, penetram na consciência dos indivíduos agentes". No mundo da pseudoconcreticidade, a diferença entre fenômeno e essência desaparece. Mas, com este mesmo autor aprendemos que o fenômeno, simultaneamente, revela e esconde a essência. Se assim não fosse, o mundo da realidade se distinguiria radicalmente do mundo do fenômeno. Por esses motivos, reconhecemos a pertinência de tal perspectiva de análise, mas também seus limites pois, "sem o fenômeno, sem a sua manifestação e revelação, a essência seria inatingível". (idem, p. 12)

A fenomenologia social, portanto, nos ajuda a não tentar chegar diretamente à essência sem buscar apreender exaustivamente o fenômeno na sua aparência. Veremos que sua contribuição para este estudo se vê confrontada pelo materialismo histórico-dialético pela categoria contradição, posto que os grupos profissionais, sua experiência, sua cultura e seus saberes se constituem como fenômenos de interações subjetivas que guardam determinações da estrutura social, ao mesmo tempo em que a apropriação de seus saberes pelo reconhecimento das formas de uso do conhecimento abstrato ajudam a recuperar o sentido da agência humana no confronto com esta mesma estrutura.

Além da fenomenologia social, consideramos também as contribuições do interacionismo simbólico. E sobre isto, vale lembrar que as orientações sobre o uso prático do conhecimento não são novas na sociologia. Abordagens teóricometodológicas inspiradas na sociologia simbólica-interacionista têm 
continuadamente salientado a autonomia da (des)ordem social que se constrói à escala micro das atividades práticas de interação social, inclusive perspectivandoa em diálogo com várias correntes da psicologia (BLUMER, 1982). Porém, muitas das pesquisas que seguem esse caminho acabam por centrar-se na análise da construção da mente e da identidade do sujeito cognitivo, ou na especificidade das significações, das crenças e dos conteúdos de conhecimento das atividades práticas locais, tendendo a ser acusadas de desenvolverem explicações subjetivistas e relativistas do conhecimento e da reflexividade social. Entendemos que a compreensão dos processos sociais que considerem a agência humana não pode prescindir do estudo da experiência dos sujeitos na produção de sua existência no plano do cotidiano e da estrutura social. Para isto, uma contribuição para se superar os limites da abordagem fenomenológica e/ou sócio-interacionista são algumas categorias de Edward Thompson (1981) sobre a experiência humana, às quais recorreremos em alguns pontos deste texto.

A abordagem do saber profissional ${ }^{4}$ como parte de uma cultura de grupo, por sua vez, ao colocar seu interesse para além da recontextualização do conhecimento e das pesquisas que visam coletar os conhecimentos e as crenças subjetivas das pessoas, procura enfocar processos sociocognitivos de aprendizagem e uso do conhecimento de forma contextual e situacional, sem desprezar influências das relações sociais institucionalizadas e relações de poder mais amplas sobre o conhecimento (QUÉRÉ \& FORNEL, 1999). Nesse sentido, entende o poder como constituinte das interações sociais e não opõe agência humana à estrutura social (CARIA, 2008, 2010).

A sociocognição - o uso do conhecimento associado à aprendizagem na interação - advém de um aporte interdisciplinar, incluindo contribuições mais recentes da psicologia cognitiva e das ciências cognitivas. Essas, porém, devem contribuir para uma compreensão da mente na perspectiva da ação social e não estritamente da organização e formas das representações mentais internas ao sujeito, como é propósito da psicologia cognitivista (EVANS, 2008; STERNBERG \& HORVATH, 1999; SUN, 2002; CARIA, 2017).

\footnotetext{
${ }^{4} \mathrm{O}$ conceito de profissional deve ser entendido no âmbito da tradição internacional de pesquisa em Sociologia dos Grupos Profissionais e sua associação, mais recente, com a Sociologia das Organizações (Dubar \& Tripier, 1998; Noordegraaf, 2007; Caria, 2013).
} 
Inicialmente, discutimos o conceito de saber profissional como 0 conhecimento em uso por profissionais em situações de trabalho, sendo constituído por dualidades epistemológica, cognitiva e social. Ao ter a ciência e a experiência como fontes, emerge de interações nos grupos profissionais em que se instauram tensões advindas das diferenças de poder em confronto com identidades coletivas e com a reflexividade social. (CARIA, 2005, 2008).

Passamos, depois, ao diálogo com as ciências cognitivas a partir do conceito de sociocognição, mantendo uma referência sociológica, isto é, colocando práticas, ações, atividades, interações, mais do que as pessoas, no centro do interesse analítico. Discutimos também o saber profissional na perspectiva da comunicação com os usuários quando, pela linguagem - meio de externalização sociocognitiva - podem se manifestar desigualdades de poder e de conhecimento entre as pessoas em interação.

\section{O Saber Profissional como objeto de investigação}

Para melhor compreender o conceito de saber, importa repetir que enfatizamos os processos de aprendizagem que decorrem do uso do conhecimento, pelos sujeitos sociais, na ação.

Assim, o saber não se confunde com o conhecimento científico, com recortes e apropriações aplicadas - conhecimento técnico e tecnológico - ou, ainda com enunciados de ordem filosófica, jurídica ou equivalentes. No escopo de nosso estudo, esses serão reconhecidos como conhecimento abstrato.

$O$ conhecimento abstrato, ainda que delimite e em grande medida defina profissões (ABBOTT, 1988; EVETTS, 2003; BRANTE, 2010), não se configura imediatamente como saberes profissionais, mas sim como uma de suas fontes. A outra é a experiência prática. No trabalho profissional processa-se uma transformação prática do conhecimento abstrato para que seja adequado à intervenção profissional em situação e na interação social, gerando uma forma situada do conhecimento: o saber profissional. Por meio deste, os membros de um grupo coordenam suas ações em situação com consciência prática; isto é, com um conhecimento tácito habitualmente utilizado no desenvolvimento de sequencias de conduta (COLLINS \& EVANS, 2007; PAVLIN et al., 2010; GHERRARDI, 2007; STERNBERG \& HORVATH, 1999; CARIA, 2017b). 
Neste processo, os critérios acadêmicos normalmente utilizados para se julgar a validade de um conhecimento - coerência dos enunciados, rigor conceitual e generalização dos problemas diagnosticados - adquirem uma relação tensional com a ambiguidade e ambivalência dos significados partilhados na interação social, com a subjetividade das interpretações dos problemas e dos casos e com a procura de eficácia para os resultados obtidos, por relação com aquilo que é prescrito socialmente e é assumido pela ideologia e saberes tácitos que suportam o poder profissional numa dada sociedade (CARIA, 2014).

Esta tensão pode ter várias interpretações teóricas. Na perspectiva dos processos de recontextualização do conhecimento abstrato, trata-se de reconhecer que o saber se organiza pela mediação que a experiência e a reflexividade do profissional fazem entre a teoria e a especificidade dos casos sobre os quais o trabalho profissional se debruça, visando uma intervenção profissional em contexto que saiba lidar com o contingente e 0 incerto dos problemas sociais a partir de princípios e regras abstratas de aplicação generalista (SHON, 1983; ABBOTT, 1988; CARIA, 2000; CARIA et al., 2012).

Complementar esta perspectiva com uma contribuição interacionista, permite também afirmar que na cultura profissional existe uma especificidade pragmática no trabalho quando este visa a atender expectativas dos usuários. Por esta especificidade, o saber resulta da interpretação do curso da interação social nos seus efeitos imediatos, cognitivos e expressivos, na atuação do outro, e suas consequências naquilo que acontece, aqui e agora.

Essa perspectiva se confronta com aquela discutida por Zarifian (1994) sobre as organizações qualificantes e aprendizes, cuja característica seria se aproveitar da imprevisibilidade da produção como origem e ocasião de aprendizagem para trabalhadores e organização. Ainda que ambas as abordagens valorizem as componentes cognitiva e comunicacional das interações no trabalho, as organizações que adotam tal perspectiva de gestão visam, na lógica da aprendizagem organizacional, a apropriação dos saberes tácitos dos trabalhadores ao formalizá-los, "tornando-os proposições explícitas e transformando-os em estruturas de rotina, que constituem a memória da organização [...] designadas pelos termos de competências organizacionais". (RAMOS, 2001, p. 207) Ao contrário disto, interessa-nos o estudo dos saberes 
profissionais muito mais como resultantes de constrangimentos e tensões que potencializam soluções no fluxo da interação no interior de um grupo profissional e, que pode, inclusive, proteger e/ou manter a coesão do grupo frente ao poder institucional. Do ponto de vista epistemológico, como indicam alguns dos estudos etnográficos desenvolvidos em Portugal (CARIA, 2000, 2011; LOUREIRO, 2008; PEREIRA, 2008; CARIA e PEREIRA, 2017) e no Brasil (RAMOS, 2011, 2015, 2017), a dualidade se manifesta numa articulação complexa, contraditória e variável, onde o implícito e o tácito parecem ter um importante papel.

Ao trazer a categoria experiência para o estudo dos saberes profissionais, Ramos (no prelo) trata da experiência direta e indireta, explicitando uma tensão desse termo nas perspectivas pragmática e histórico-dialética, exposta a seguir.

Os pragmatistas, ao considerarem que todos os conhecimentos autênticos resultam da experiência direta, elidem o fato de que o homem não pode ter uma experiência direta de tudo, razão pela qual a maior parte dos nossos conhecimentos é, na realidade, o produto de uma experiência indireta. No trabalho profissional, certamente ocorre a experiência direta com situações, tornandose uma fonte empírica de conhecimentos. A formação profissional/escolar, por sua vez, é uma experiência indireta com a realidade, fonte de conhecimentos já produzidos por outros sujeitos no processo histórico-social de apropriação da realidade.

Nas situações de trabalho, experiência direta e indireta com a realidade se encontram como práxis produtiva e social. A elaboração teórico-metodológica dos saberes profissionais aqui expostas originária de pesquisas realizadas em Portugal enfrenta contradições no Brasil. Por ser um país de capitalismo dependente (FERNANDES, 2006), a acumulação de capital se baseou na superexploração do trabalho e na desqualificação da maioria dos trabalhadores, manifesta na baixa escolaridade média da população.

Assim, enquanto em Portugal se estudam saberes de profissionais de nível superior (CARIA, 2010), no Brasil, outras pesquisas (RAMOS, 2011, 2015, 2017) têm-se voltado para profissionais de nível médio, trabalhadores técnicos da saúde. Muitos desses trabalhadores obtiveram antes a experiência prática no trabalho para, depois, realizarem a formação técnica. Ademais, eles desenvolvem seu trabalho com baixa autonomia e elevada subordinação ao profissional de nível superior. 
Esses trabalhadores possuem baixo poder econômico, social e simbólico. Suas atividades têm por base o conhecimento científico que orienta procedimentos técnicos, mas o acesso a esse conhecimento de forma sistematizada foi delimitado pelo nível de ensino exigido, de modo que os conteúdos selecionados pelas escolas que os formam tendem a ser restritos àqueles considerados necessários a orientar bons procedimentos práticos (RAMOS, 2010). Mesmo com essa configuração, o conhecimento científico está presente na atividade de trabalho, seja explícita ou implicitamente; e os trabalhadores fazem algum uso deles. Tais usos sofrem influência de determinações estruturais, tais como as condições de classe, as políticas de educação básica e de educação profissional; além de relações de poder instauradas entre subalternos e superiores e entre pares de um mesmo contexto profissional (RAMOS, 2014). Essa realidade desafia a teoria original ao confrontála com as relações sociais de produção em uma formação social concreta como o Brasil.

Ao estudar os saberes profissionais de técnicos de nível médio de vinte equipes da Saúde da Família das cinco regiões brasileiras (RAMOS, 2017), por exemplo, identificamos uma importante capacidade resolutiva das equipes, porém, em circunstâncias débeis e/ou heterogêneas de formação no interior da equipe. No que tange à educação formal, tendo-se a ciência como uma das fontes, tais debilidades e/ou heterogeneidades decorrem de um lado, dos limites da formação inicial; e de outro, da insuficiência da formação continuada. Já em relação aos aprendizados da prática, quando a experiência predomina como fonte de conhecimentos, a manutenção de relações hierárquicas, ao invés de tornarem a heterogeneidade da formação em oportunidades de aprendizagem mútua, acabam por reiterá-las, perdendo-se, assim, o potencial formativo da experiência profissional vivida coletivamente e confirmando a configuração mais de equipes fragmentadas em seus interesses e poder do que por eles integradas.

\section{Cultura Profissional: um poder e um saber coletivo situado}

Situar o conceito de saber profissional no âmbito de uma cultura supõe considerar que, independentemente da epistemologia-fonte usada ser científica 
ou ser prática e experiencial, ele constrói-se na interação com o outro, num processo de ajustamento de expectativas mútuas e de atribuição de significados às coisas e às ações do meio social envolvente. Nesta perspectiva interacionista sobre o conceito de cultura, pretende-se evitar que, por um lado, o conhecimento usado pelo indivíduo para agir numa dada situação seja concebido como independente do uso que o seu interlocutor lhe dá, isto é, dos significados atribuídos pelo outro à mesma situação. Porém, como já afirmamos, pretende-se evitar que o conhecimento seja perspectivado somente como o resultado de um processo socializador de conformação dos indivíduos a estruturas simbólicas ou a instituições culturais no qual a experiência possuída seja mais ou menos equivalente ao conhecimento social herdado (BLUMER, 1982).

Nesse sentido, propomos mais uma vez o diálogo com o historiador Thompson (1981), quando este afirma que considerar os valores somente como impostos pela classe dominante seria um equívoco em relação a todo o processo social e cultural: "ao negar a ideia de imposição heterônoma, ele não desvincula completamente os valores da ideologia, mas os coloca no plano da cultura, o que significa reconhecê-los como experiência vivida" (RAMOS, 2018).

No estudo dos saberes profissionais, o conceito de cultura põe em evidência que os conhecimentos abstratos e experienciais usados em situação não são apenas uma criação individual ou um produto institucional. São um processo social de construção que tem, simultaneamente, motivações cognitivas de ação e resolução de problemas comuns e de comunicação de significações variadas capazes de exprimir e negociar uma identidade social partilhada. É a conjugação destas duas motivações que permite dizer que a cultura que constrói em situação o saber profissional está ao mesmo tempo construindo um grupo de pares: associando uma prática situada de trabalho com uma diferenciação grupal identitária (QUEIROZ \& ZIOTKOWSKI, 1997).

No entanto, como indica a fenomenologia social, o que está em causa não é só a construção social de um grupo profissional. Ao desenvolver-se na interação social um cotidiano compartilhado em comum e um repertório de experiências sociais coletivas, a cultura profissional constrói um mundo social próprio, onde os outros existem por referência aos limites e aos horizontes desse mundo auto referenciável. A realidade social é suportada por uma atitude natural que apaga o 
processo cultural de construção dessa realidade, fazendo com que a percepção, a identidade e a reflexividade da cultura profissional dependam em primeiro lugar da consciência prática que existe na interação social sobre o que se acredita ser o mundo (SCHUTZ, 1994; DENYS, 2001). Neste contexto, todo o uso que se fizer do conhecimento abstrato institucionalizado está dependente dos limites e dos horizontes que uma cultura profissional herda, tem e potência quando constrói a realidade social e quando reproduz uma ordem interacional.

Se ampliarmos a construção do objeto na perspectiva histórico-dialética, os grupos profissionais seriam entendidos como particularidades sociais que podem ou não se identificar como classe trabalhadora. Não é possível partir-se de um ou outro pressuposto, mas trata-se de uma questão que o pesquisador pode se colocar ao ser coerente com essa filosofia. Neste caso, tensionando tanto com a fenomenologia social, quanto com o pragmatismo, teria que se colocar a categoria experiência humana no plano das relações sociais de produção, para além das interacionais; e a cultura, como materialização dessa experiência a qual, por sua vez, "exerce pressões sobre a consciência social existente" (THOMPSON, 1981, p. 16). Nesse sentido, o estudo dos saberes de grupos profissionais poderia ajudar a compreender dinâmicas e processos pelos quais os trabalhadores se afirmam, em suas relações de trabalho, como sujeitos das relações sociais de produção e, assim, resistem e elaboram formas de enfrentamento à dominação.

As pesquisas que informam este texto não se colocaram tal desafio 5 . Porém, o escopo teórico até então construído, não ignora que a construção de uma cultura profissional é constrangida por poderes de estruturas e instituições sociais exteriores mais amplos e não deixa de poder gerar, em articulação com outros processos simbólicos e culturais (incluindo o conhecimento abstrato), consequências sociais que poderão ir além da realidade e da identidade herdadas e reproduzidas por um dado grupo.

\footnotetext{
${ }^{5}$ As pesquisas coordenadas pelo primeiro autor deste artigo valem-se predominantemente da contribuição da fenomenologia social, enquanto as da segunda autora têm-se apoiado na teoria sobre saberes profissionais por ele desenvolvida, mas propõem extrapolar a análise do plano micro para o macrossocial, a partir do materialismo histórico-dialético, com contribuições do materialismo cultural de Raymond Williams, do conceito de experiência em Edward Thompson e de práxis em Antônio Gramsci, ainda delimitado ao plano teórico e não empírico. O confronto dessas perspectivas tem-se mostrado virtuoso, para os autores, no estudo dos saberes de grupos profissionais ao ajudar a compreender dinâmicas e processos desiguais de ativação e mobilização de conhecimento tácito-experiencial e conhecimento explícito-abstrato, pelos quais os trabalhadores se podem afirmar como sujeitos das relações sociais e, assim, resistir e elaborar formas de enfrentamento à dominação socio-econômica e/ou socio-cultural.
} 
A ordem social interacional que é construída pela cultura contém prescrições, normas e regras gerais que the são externas, mas que precisam ser atualizadas à medida que o processo de interação social ocorre porque ela não está acima da história, nem é obrigatoriamente homogênea.

Esta dualidade, estruturante da vida social, permite afirmar que toda a ordem cultural - reproduzida pelo poder-constrangimento - contém uma história de desordens, de desigualdades e conflitos sociais e culturais - reproduzida pelo poder-capacitador - que também precisa ser regulado na interação social. Tratase de uma dualidade do poder que introduz uma descontinuidade nas interações sociais. Aquilo que se herda como conhecimento provado e validado por gerações anteriores não é necessariamente equivalente àquilo que se exprime e prática na situação; isto é, a identidade social que garante a reprodução do passado no presente opera em situação sem ter que estabelecer uma equivalência automática entre o interiorizado-incorporado e o exteriorizado-comunicado.

Numa interpretação menos psicológica do interacionismo simbólico fala-se de uma tensão (de um potencial desencaixe) na identidade social de um grupo entre aquilo que é atribuído pelos outros a nós e aquilo que herdamos da nossa experiência coletiva e que nos permite ter uma expectativa social sobre os outros (DUBAR, 1997; CARIA et. al., 2017).

$\mathrm{Na}$ referência praxiológica reconhece-se que pode existir uma descontinuidade (uma histeresis da prática que manifestaria um envelhecimento do habitus) entre as estruturas sociais e simbólicas passadas herdadas, nas quais os grupos sociais são socializados, e as estruturas de poder atuais, nas quais os grupos sociais atuam como agentes simbólicos e culturais (BOURDIEU, 1972, 1997).

As ideias de "experiência herdada" e "experiência transformada" de Thompson (1998), por sua vez, expressam o movimento de construção, transmissão e transformação cultural na classe. As formas de resistência à dominação nas estratégias de organização cotidiana do povo visam, muitas vezes pela defesa e manutenção de sua cultura, garantir condições para sua existência.

$\mathrm{Na}$ nossa perspectiva existe uma interdependência entre a dualidade do poder e a dualidade das mentes que organizam os saberes profissionais. Ambas se encontram na construção cultural dos grupos profissionais ao nível da 
interação social. A primeira dualidade salienta o fato de ser possível haver improviso prático apesar dos constrangimentos externos e das consequências não previstas da ação. A segunda salienta o fato de poder haver uso do conhecimento abstrato e uma atitude reflexiva face ao mundo social, apesar da subordinação da cultura aos processos que ordenam o social na interação. Vejamos como estes dois processos podem ser pensados em conjunto com base nas conclusões dos estudos etnográficos que temos desenvolvido, que referenciamos anteriormente.

O trabalho profissional sofre constrangimentos externos porque é alvo de expectativas institucionais e sociais. Pode-se supor que ao necessário alinhamento de seus procedimentos a essas expectativas corresponda algum nível de subordinação da cultura do grupo profissional à ordem social. As interações no interior do grupo tenderiam a se orientar em defesa da sua coesão frente aos constrangimentos e, nesse sentido, o movimento predominante seria evitar o conflito e buscar o consenso, afastando ou silenciando as perturbações. Sob tal lógica, o que tenderia a predominar na interação seriam condutas automáticas; isto é, agir como de costume, correspondendo às expectativas mútuas influenciadas pela defesa da coesão interna face aos constrangimentos externos.

As interações realizadas nesses termos são produtoras do senso comum compartilhado pelo respectivo grupo - um conhecimento tácito coletivo (Collins, 2010) - que consolidam uma cultura profissional. Porém, há situações em que as tensões não são eliminadas pelo consenso nem acirradas ao ponto de se irromper o conflito, pois a construção de uma identidade social partilhada, numa dada conjuntura, não pressupõe práticas iguais.

Nesses casos, como as ações reprodutoras se desestabilizam, os automatismos não conseguem manter o fluxo da interação. Surgem os improvisos, que advêm de processos sociocognitivos não-representacionais; isto é, da intuição, da capacidade de associar experiências com expectativas e de selecionar oportunidades e alternativas. Os improvisos se tornam aprendizagens mútuas para as quais as divergências de sentido, desde que negociadas internamente, tornam-se uma oportunidade, e compõem os saberes profissionais juntamente com os automatismos consolidados na prática do grupo profissional. 
Ao mesmo tempo, as respostas do grupo profissional a constrangimentos e expectativas externas podem levar à afirmação de interesses, projetos e ações comuns que exigem da cultura profissional o uso de conhecimento abstrato e o investimento na reflexividade profissional. Nesses casos, a coesão interna visa tanto manter o fluxo das interações, mas também assegurar uma relativização do seu etnocentrismo cultural, potenciando o uso da razão teórica e critica em relações sociais mais amplas, inclusive para atuar sobre os constrangimentos que a subordinam. O saber profissional, neste caso, se revela em competências analíticas, em articulação e contraposição às de tipo automáticas e intuitivas.

Enfocamos até aqui as interações no interior do grupo profissional por relação com a dualidade de processos, mais ou menos articulados ou descontínuos entre consenso-improviso e divergência-consciência crítica. Mas as que se processam deste com os usuários dos serviços também têm relevância e trazem outros elementos para a análise, dado que neste caso trata-se de relações multiculturais.

Estas relações podem ser reproduzidas automaticamente num sistema de papéis e estatutos que legitima as diferenças de poder e conhecimento entre profissionais e usuários, desde que na interação social esses participantes tenham uma atitude de conformação mútua com as normas sociais institucionalizadas. Sempre que esta conformação normativa não ocorre, à escala micro da interação acumulam-se tensões e perturbações nas expectativas mútuas. Neste quadro, as culturas profissionais têm uma de duas alternativas extremas: ou se fecham no seu etnocentrismo profissional e geram exclusão dos usuários menos conformados, fazendo uso da violência simbólica para que as relações assimétricas na comunicação sejam reproduzidas; ou relativizam o seu etnocentrismo e geram inclusão social procurando desenvolver relações de compreensão também com os usuários que mais perturbam a interação.

No primeiro caso, a cultura profissional usa o seu poder constrangedor e em consequência o conhecimento prático e experiencial frente ao senso comum dos usuários sobre os problemas sociais em que estão envolvidos que é considerado irrelevante e supérfluo para o saber profissional. No segundo, ao contrariar e minimizar o uso da violência simbólica, a cultura profissional usa o seu poder capacitador para possibilitar uma ressignificação do seu saber pelo 
senso comum dos usuários, abdicando do monopólio do conhecimento em benefício de uma compreensão mútua menos desigual. A comunicação, uma mediação fundamental para a eficácia do trabalho profissional, ocorre pelo encontro contraditório entre a linguagem profissional e a linguagem comum dos usuários.

Entre esses dois extremos estão outras possibilidades que dependem não só do profissional, mas também da receptividade do usuário, porque a rigor, não há uma fronteira clara, ou uma dicotomia, entre as duas soluções. Como referimos, o poder constrangedor não se opõe ao poder capacitador dado que, por um lado, o uso do conhecimento abstrato pode dar ao profissional uma consciência crítica de que precisa desenvolver relações de compreensão mútua com os usuários, mas não é por isso que passa a ter automaticamente o saber prático e experiencial para encontrar formas e meios de expressão a uma comunicação menos assimétrica. O profissional precisa improvisar, valendo-se de sua experiência anterior para lidar com usuários com condutas desviantes. Assim, acaba por construir o saber profissional necessário a esse fim.

Em conclusão, a interdependência entre dualidade de poder e dualidade das mentes nesse tipo de interação se processaria da seguinte forma: quanto mais o conhecimento abstrato e a reflexividade profissional forem orientados para a compreensão do usuário, menor o recurso à violência é visto como um meio legítimo de ação, ainda que isso não seja suficiente para se saber melhor lidar com a diferença cultural; quanto mais houver experiência de improvisar para gerar compreensão, menos o uso da violência será visto como um meio cultural do grupo, ainda que isso não seja suficiente para se saber porque é que em cada caso um dado improviso é mais eficaz do que outros. A seção que se segue aprofunda o estudo do saber profissional nessas duas perspectivas.

\section{- Saber Profissional como representação situada: uma abordagem cognitiva da ação}

Nossa abordagem cognitiva do saber profissional não opõe os princípios da representação simbólica aos da ação situada, tal como se pode encontrar nos debates das Ciências Cognitivas (QUÉRÉ \& SCHOCH, 1998; VARELA et al., 2003; VERA \& SIMON, 1993; FRAWLEY, 1997; WILSON, 2002). O que nos 
parece fundamental é reconhecer que o conhecimento produzido a partir de representações mentais do mundo objetivo tem limites para domínios indefinidos de tarefas como a experiência cotidiana.

Na seção anterior referimo-nos à dualidade epistemológica que produz os saberes profissionais: a prática e a teoria. Abordaremos, agora, a dualidade sociocognitiva, dada à coexistência de formas de pensamento de tipo pragmático e analítico no trabalho profissional. Esta dualidade é abordada pelas teorias da mente dual (EVANS, 2009, 2008; SUN, 2002) que nos ajudam a compreender a cognição sendo constituída por processos de representação, percepção e associação que se interconectam no agir em situação.

Nessa abordagem, o cérebro humano conteria dois sistemas paralelos de cognição, ou duas mentes: uma pragmática e outra analítica. A primeira produziria, armazenaria e utilizaria conhecimentos que são inerentemente implícitos envolvendo a percepção, a atenção, a associação e a aquisição de habilidades motoras, além de sensações e respostas emocionais e intuitivas. Ela opera predominantemente, através dos processos de tipo 1 - rápidos, automáticos, com alta capacidade de processamento a baixo esforço. Trata-se de automatismos que orientam o comportamento diretamente sem precisar de atenção controlada, ao reconhecerem imediatamente padrões e regularidades de ação que não passam pela consciência. A segunda mente usaria conhecimento explícito e operaria primariamente através de processos de tipo 2 - lentos, controlados, de capacidade limitada e elevado esforço. Esses incluem raciocínio lógico, analítico e hipotético, via suposições e simulações mentais conscientes baseadas em princípios e regras explícitos.

Ainda que os processos de tipo 1 formem o sistema designado como mente pragmática e os de tipo 2, o sistema da mente analítica, considera-se pertinente - para não se ficar apenas no estudo psicológico das estruturas cognitivas internas ao sujeito - a hipótese da existência de ambos os tipos de processamentos em cada uma das mentes (Evans, 2009): primeiro, a extração de saber da prática; segundo, a recontextualização rotineira do saber. No primeiro os conhecimentos implícitos poderiam ser também processados analiticamente na forma de associações e comparações seletivas, relativas à reflexão a partir da experiência entre diferentes contextos de ação. No segundo, os conhecimentos 
explícitos poderiam ser processados rápida e automaticamente, visando a recontextualização de princípios e regras gerais, na forma de normas e rotinas práticas de pensamento e ação recorrentemente aplicadas.

Para nós, é essencial esta hipótese, pois dela, como veremos, depende o próprio conceito de saber profissional como construção social na articulação entre mentes-epistemologias do conhecimento (CARIA, 2017a).

\section{O Saber Profissional na interação multicultural: uma abordagem na perspectiva da comunicação}

O papel da linguagem na interação entre profissionais e usuários - aquilo que designamos como a componente comunicacional da ordem interacional nas relações multiculturais - é também relevante, uma vez que nesse tipo de interação as desigualdades de poder e conhecimento manifestadas na comunicação podem ser muito marcantes. Sendo assim, o estudo da sociocognição na perspectiva interacional buscaria também entender o saber profissional sob o enfoque da comunicação com o outro (com outras culturas), considerando a linguagem como externalização sociocognitiva; ou seja, como mediação que mantêm o fluxo da interação social pelo diálogo. Para tal propósito, encontramos na abordagem sobre os gêneros discursivos de Bakhtine (1977), uma possibilidade teórica.

Para o autor, as falas sociais em uso numa situação medeiam a relação entre o sujeito, a língua e o mundo, fixando o regime social de funcionamento da língua que são os gêneros. Não se trata de uma norma, ou de regras explícitas de uso da linguagem, mas sim de um estoque de enunciados mutuamente esperados, protótipos de maneira de dizer ou de não dizer num espaço sociodiscursivo, que retêm a memória social nos atos comunicativos. Eles trazem os subtendidos - o conhecimento implícito na comunicação que constitui o tácito coletivo (COLLINS, 2010) - que regem as relações com os objetos e entre as pessoas, tradições adquiridas que se exprimem e se preservam nas palavras. Quando partilhado, o gênero permite o fluxo do diálogo e, portanto, a partilha de um quotidiano de vivências implícitas comuns, no sentido fenomenológico. Quando não partilhado, pode travar o fluxo do diálogo, evidenciando perturbações 
nas expectativas mútuas de interação, para as quais é necessário encontrar soluções ajustadas à (des)ordem interacional.

Para enfocar o saber profissional nesta perspectiva, consideramos a linguagem profissional como um gênero discursivo, constituída por significados científicos explícitos e por outros tácitos compartilhados pelo grupo profissional. Os usuários dos serviços, por sua vez, entram em interação com os profissionais a partir de sua linguagem diária corrente que não é a mesma do gênero discursivo profissional. Mas os usuários não conformam um grupo cultural com identidade própria, dada a grande diversidade de origens sociais e culturais destes, especialmente quando se trata de serviços profissionais no âmbito do desenvolvimento de políticas públicas (orientação que temos privilegiado no contexto dos nossos trabalhos anteriores). Por esta razão, abordamos a componente comunicacional desse tipo de interação a partir da orientação que o profissional confere à sua fala com o usuário, uma vez que podemos falar da existência de um gênero discursivo do grupo profissional, mas não podemos fazer o mesmo em relação aos usuários.

No âmbito de uma cultura profissional, o gênero discursivo pode ser entendido como a externalização da cultura pela linguagem e contribui para a unidade do grupo. Porém, o gênero discursivo profissional pode contribuir também para o fechamento etnocêntrico da cultura profissional, tornando-se um obstáculo para a fluência da comunicação na relação multicultural entre profissional e usuário, uma vez que as dualidades de poder e de conhecimento institucionalmente reproduzidas e legitimadas se podem estender, na comunicação, para uma forma de dualidade de poder sobre a linguagem.

Profissional e usuários dominam gêneros discursivos distintos, sendo próprio dessa interação o predomínio do gênero discursivo profissional que organiza e externaliza o saber profissional necessário e esperado pelo usuário para a eficácia na resolução de seus problemas. No enfrentamento dessa dualidade, o profissional pode se dispor a ressignificar a linguagem profissional com a linguagem comum, a fim de proporcionar maiores condições de compreensão pelo usuário. Trata-se da orientação da fala para a partilha. Diferentemente, o profissional pode orientar sua fala demarcando a diferença entre sua linguagem e a linguagem comum. Designamos tal orientação como 
distinção. Podemos dizer, então, que a interação multicultural entre profissional e usuário ocorre em contextos sociodiscursivos formados pelo encontro entre as orientações das respectivas falas. Quando a fala profissional orientada pela partilha encontra-se com a fala receptiva do usuário, tem-se um contexto de coordenação compreensiva entre os sujeitos; contexto este no qual interesses do profissional e do usuário passam a convergir.

\section{Conclusão}

Buscamos compreender a sociocognição uma perspectiva interdisciplinar, com contribuições da sociologia do conhecimento, da fenomenologia social, do interacionismo simbólico e das ciências cognitivas, considerando diálogos em alguns aspectos com o pensamento histórico-dialético. A construção do conceito de saber profissional como uma referência organizativa da cultura profissional enfocou o processo de transformação do conhecimento científico da profissão por práticas sociais comuns. Privilegiou-se o enfoque analítico que ressalta e problematiza as dualidades que se confrontam e se articulam na dinâmica interacional no interior do grupo profissional e na relação deste com os usuários dos serviços.

$\mathrm{Na}$ abordagem do saber profissional, discutimos as dualidades epistemológica (teoria e prática) e cognitiva (mentes analítica e pragmática) a partir das quais este saber é produzido. Compreendendo que o saber profissional só se produz em interação com o outro, num processo de ajustamento de expectativas mútuas e de atribuição de significados às coisas e às ações do meio social envolvente, demonstramos que seu caráter interacional e coletivo conforma a cultura profissional.

Numa perspectiva fenomenológica, discutimos que a percepção, a identidade e a reflexividade da cultura profissional depende também da consciência prática dos sujeitos na interação e não só do que seus determinantes estruturais. Nesse âmbito, destacamos a dualidade de poder que se interconecta com a dualidade epistemológica e cognitiva do saber profissional, privilegiando as perspectivas da descontinuidade que existe entre o herdado e o determinado social e estruturalmente e as práticas sociais que implicam novos improvisos ou 
análises em situações atuais. O detalhamento analítico da dinâmica interacional do grupo na perspectiva cognitiva nos levou a discutir a relação entre os automatismos, a intuição e a capacidade de análise dos profissionais, as quais exprimem a flexibilidade que as situações impõem às dimensões epistemológica e cognitiva do conhecimento. Não nos furtamos a questionar as possibilidades desse estudo na perspectiva histórico-dialética, o que exigiria dar centralidade ao conceito de classe social e a discussão da categoria experiência e cultura nesse sentido. Apontamos, porém, os limites desse movimento no diálogo aqui construído.

Externamente ao grupo, optamos por enfocar a dualidade de poder que existe na relação deste com os usuários do trabalho profissional, posto que essa relação é, necessariamente, orientada pela desigualdade de conhecimento legitimada e reproduzida institucionalmente. Conformam-se, nesses casos, interações de tipo multiculturais nas quais a comunicação torna-se uma componente fundamental, dado que nesta se reproduzem as desigualdades anteriores. A forma como o profissional usa a linguagem pode ser decisiva para a eficácia do seu trabalho, especialmente quando o usuário não legitima a desigualdade de poder e reconhece as perturbações na interação como desafios profissionais.

Com esta problemática, demonstramos que distintos contextos sociodiscursivos podem instaurar na relação multicultural, dependendo da orientação da fala dos respectivos interlocutores, o que nos deu indicações sobre como o profissional pode ser levado a agir a partir das expectativas dos usuários, de suas próprias expectativas em relação ao seu conhecimento e ao papel dos usuários e, finalmente, em relação às expectativas de seu grupo profissional. Em todas as situações, por implicar negociação de significados entre os sujeitos que seja eficaz para a manutenção do fluxo da interação, as referências identitárias do grupo parecem ser fundamentais para que o encontro multicultural não seja inviabilizado.

Do ponto de vista teórico-metodológico, apresentamos aqui duas aprendizagens. A primeira, de que uma teoria cujos conceitos precisam ser historicizados face à realidade empírica que pretende explicar talvez requeira o diálogo com outras teorias para atender a uma exigência do próprio objeto 
científico. Nesse sentido, é possível que os conceitos experiência e cultura possam nos orientar no estudo de grupos sociais para apreendermos sua materialidade como classe. Esta pode ser também uma razão para se estudar o senso comum, o conhecimento prático, os saberes de grupos profissionais a partir de sua própria experiência e não somente dos processos formais de aquisição do conhecimento científico.

Como afirmamos na introdução deste texto, a possibilidade do diálogo entre o materialismo histórico-dialético e a fenomenologia estaria em que o primeiro não visa transcender imediatamente o fenômeno em busca da essência, mas reconhece não se poder ir além do fenômeno sem primeiro buscar compreendê-lo exaustivamente na sua manifestação empírica. Compreender o fenômeno na sua manifestação empírica parece-nos ser o projeto da fenomenologia. O do materialismo é tentar captar o que o fenômeno revela e, ao mesmo tempo, esconde.

\section{Referências}

ABBOTT, Andrew. The system of professions: an essay on the division of expert labor. Chicago and London: The University of Chicago Press, 1988.

BAKHTINE, Mickail. Le marxism et la philosophie du langage: essai d'application de la method sociologique en linguistique. Paris: Minuit, 1977.

BERNSTEIN, Besil. Pedagogy, symbolic control and identity. London: Taylor \& Francis, 1996.

BOBBIO, Norberto. Nem com Marx nem contra Marx. São Paulo: Editora Unesp, 2006.

. The structuring of pedagogic discourse. London: Routledge, 1990.

BLUMER, Herbert. El interaccionismo simbolico: perspectiva y metodo. Barcelona: Hora, 1982.

BOURDIEU, Pierre. Méditations Pascaliennes. Paris: Seuil, 1997.

. Esquisse d'une theorie de la pratique: précédé de trois études d'ethnologie kabyle. Paris, Genève: Droz, 1972.

BRANTE, Thomas. Professional fields and truth regimes: in scharch of alternative approaches. Comparative Sociology, n.9, p. 843-886. 2010. 
BRASSAC, Christian. Une vision praxéologuique des architectures de connaissances dans les organizations. Revue d'Anthropologie des Connaissances, n.1, p. 121-135. 2007.

CARIA, Telmo. A constituição do saber profissional: uma contribuição interdisciplinar sobre a dualidade do uso social do conhecimento, Análise Social no224 (vol.LII-3), pp.498-532. 2017a.

O situado, o tácito e o quotidiano do saber: contribuições microssociológicas. In: Caria, Telmo H; Pereira, Fernando A. (eds.), Saber profissional em Serviço Social: uma perspectiva etnográfico-situacional (39-60). Viseu: Psicosoma, 2017b.

- Hierarquias de conhecimento e saber profissional. Cadernos de Pesquisa, v.45, n.154. 2015.

. O uso do método etnográfico no estudo do trabalho e do conhecimento profissionais. In: TORRES, Leonor; PALHARES, José Augusto. Metodologias de Investigação em Ciências Sociais da Educação. Vila Nova de Famalicão: Húmus, 2014. p.39-64.

O trabalho profissional burocrático: modelo de análise sobre a profissionalização do trabalho social em organizações do sector não lucrativo em Portugal. Dados: Revista de Ciências Sociais, v.56, n.4, p.803-839. 2013.

. A Perspectivar a intervenção social: reflexões e dados sobre o trabalho profissional e o uso do método etnográfico no terceiro sector. In: SILVA, P.; SACRAMENTO, O.; PORTELA, J. Etnografia e Intervenção Social. Lisboa: Colibri. 2011. p. 271-286.

A mobilização de conhecimento em situação de trabalho profissional. In: FARTES, V.; ROSELI, M. Currículo, formação e saberes profissionais. Bahia: EDUFBA. 2010. p.165-193.

. O uso do conceito de cultura na investigação sobre profissões. Análise Social, v.XLIII, n.4, p.749-773. 2008.

- Itinerário de aprendizagens sobre a construção teórica do objecto saber. Etnográfica, v.11, n.1, p.215-250. 2007.

A cultura profissional dos professores: $O$ uso do conhecimento em contexto de trabalho na conjuntura da reforma educativa nos anos 90. Porto: Fundação Calouste Gulbenkian/Fundação para a Ciência e a Tecnologia, 2000.

. Saber profissional. Coimbra: Almedina, 2005.

CARIA, Telmo e PEREIRA, Fernando, eds. Saber profissional em Serviço Social: uma perspectiva etnográfico-situacional (pp). Viseu: Psicosoma, 2017. 
CARIA, Telmo H., SOUSA, Paula e ALMEIDA, José Luís. Identidade profissional institucional: actualidade da pesquisa em Serviço Social, Sociologia, Problemas e Práticas, no85, pp.145-165. 2017.

CARIA, Telmo; RAMOS, Marise. Professional Cultures and Knowledge: an interdisciplinary perspective. In: COSTA E SILVA, Ana Maria e APARÍCIO, Miriam T. (Org.). International Handbook of professional identities. 1ed.California: Scientific \& Academic Publishing, USA, 2015, v. 1, p. 66-90.

CARIA, Telmo; CESAR, Fillipa.; BILTES, Raquel. A profissionalização da Sociologia e o uso dualístico das Ciências Sociais. Configurações, n.9, p.15-36. 2012.

FERNANDES, Florestan. Ensaio de interpretação sociológica. São Paulo: Globo, 2006.

COLLINS, Harry; EVANS, Robert. Retinking expertise. Chicago: The University of Chicago Press, 2007.

COUTER, John. Mind in action. Cambridge: Polity Press, 1989.

DENYS, Cuche. La notion de culture dans les sciences sociales. Paris: La Découverte, 2001.

DUBAR, Claude. A socialização: a construção das identidades sociais e profissionais. Porto: Porto Editora, 1997.

Colin, 1998.

;TRIPIER, Pierre. Sociologie des Professions. Paris: Armand

DUBOIS, Michel. La nouvelle sociologie des sciences. Paris: Presses Universitaires de France, 2001.

EVANS, Karen; GUILE, David e HARRIS, Judy. Rething work-based learning: for education professionals and professionals who educate" in Margaret Malloch, Len Cairns, Karen Evans e Bridget N. O'Connor (eds.) The sage handbook of workplace learning. London: Sage, pp. 149-164. (2011).

EVANS, Jonathan. How many dual-process theories do we need? One, two, or many? In: EVANS, Jonathan; FRANSKISH, Keith. Two minds: dual processes and beyond. New York: Oxford Press, 2009. p.33-54.

. Dual-processing accounts of reasoning, judgment, and social cognition. Annual Review of Psychology, n.59, p.255-278. 2008.

EVETTS, Julia. The sociological analysis of professionalism: occupational change in the modern world. International Sociology, n.18, p.395-415. 2003.

FRAWLEY, William. Vygotsky and cognitive science: Language and the unification of the social and computational mind. Cambridge: Havard University Press, 1997. 
KOSIK, Karel. Dialética do Concreto. Rio de Janeiro: Paz e Terra, 1976

LOUREIRO, Alberto. O trabalho técnico-intelectual em educação de adultos: contribuição etnossociológica para a compreensão de uma ocupação educativa. Cascais: Sururu, 2008.

RAMOS, Marise. A experiência no pragmatismo e na filosofia da práxis: uma reflexão para o estudo dos saberes profissionais. In: TIRIBA, Lia e MAGALHÃES, Lívia. Experiência, o termo ausente? Campinas: Navegando, 2018.

. Processo de Trabalho dos Técnicos em Saúde na perspectiva dos saberes, práticas e competências. 2017. (Relatório de pesquisa).

- Saberes, Competências e Cultura Profissionais dos Trabalhadores do Sistema Único de Saúde (SUS): o processo de reconstrução do conhecimento na relação Trabalho e Educação. 2015. (Relatório de pesquisa).

- O estudo de saberes profissionais na perspectiva etnográfica: contribuições teórico-metodológicas. Educação em Revista (UFMG. Impresso), v. 30, p. 105-125, 2014.

- Saberes, Competências e Cultura Profissionais dos Trabalhadores do Sistema Único de Saúde (SUS): o processo de reconstrução do conhecimento na Escola e no Trabalho. 2011. (Relatório de pesquisa).

Cortez, 2001.

Pedagogia das Competências: autonomia ou adaptação? São Paulo:

RAMOS, Marise; CARIA, Telmo. Une proposition théorique et méthodologique pour l'étude des savoirs professionnels. Travail et Apprentissages, v. 16, p. 143155, 2017.

NOORDEGRAAF, Mirko. From pure to hybrid professionalism: present day professionalism in ambíguos public domains. Administration \& Society, v.39, n.6, p.761-785. 2007.

PACI, Enzo. Función de las ciencias y significado del hombre. México: Fondo de Cultura Económica, 1968.

PAVLIN, Samo.; SVETLIK, Ivan.; EVETTS, Julia. Revisiting the role of formal and pratical knowledge from sociology of professions perspective. Current Sociology, v.58, n.1, p.94-118. 2010.

PEREIRA, Fernando. Identidades e saberes profissionais no trabalho técnico em contextos associativos agrários de Trás-os-Montes e Alto Douro. Cascais: Sururu, 2008.

PHARO, P.; BOUVIER, A.; BORZEIX, A. Sociologie et connaissance: nouvelles approches cognitves. Paris: CNRS éditions, 2003. 
QUEIROZ, Jean Manuel; ZIOTKOWSKI, Marek. L'interactionisme symbolique. Rennes: Presse Universitaires de Rennes, 1997.

QUÉRÉ, Louis; FORNEL, Michel. La logique des situations. Paris: École des Hautes Études em Siences Sociales, 1999.

QUÉRÉ, Louis.; SCHOCH, Cynthia. The still: neglected situation? Réseaux, v.6, n.2, p.223-225. 1998.

SAWCHUK, Peter (2011), Researching workplace learning: na overview and critique, in Margaret Malloch, Len Cairns, Karen Evans e Bridget N. O'Connor (eds.) The sage handbook of workplace learning. London: Sage, pp. 165-180.

SCHUTZ, Alfred. Le chercheur et le quotidien. Paris: Méridiens Klincksieck, 1994.

SHON, Donald. The reflective practitioner. USA: Basic Books/Harper Collins Paper, 1983.

STERNBERG, Robert e HORVATH, Joseph. Tacit knowledge in professional practice. New York/London: Routledge, 1999.

SUN, Ron. Duality of mind: a bottom-up approach toward cognition. New Jersey/London: Lawrence Erlbaum Associates Publishers, 2002.

THOMPSON, Edward. A Miséria da Teoria ou um planetário de erros, uma crítica ao pensamento de Althusser. Rio de Janeiro: Zahar Editores,1981.

. Costumes em comum. Estudos sobre a cultura popular tradicional. Rio de Janeiro: Companhia das Letras, 1998.

VARELA, Franscisco.; EVAN, Thompson; ROSCH, Eleonor. A mente incorporada: ciências cognitivas e experiência humana. Porto Alegre: Artmed, 2003.

VERA, Alonso e SIMON, Herbert. Situated action: a symbolic interpretation. Cognitive Science, n.17, p.7-48. 1993.

WILSON, Margareth. Six views of embodied cognition. Psychonomic Bulletin \& Review, v.9, n.4, p.625-636. 2002.

ZARIFIAN, Phillipe. Competénces et Organization Qualificante em Milieu Indrustriel. In: La Compétence: Mythe, Construction ou Réalité? Paris: L'Harmattan, pp. 111-134, 1994.

Recebido em: 27 de fevereiro de 2018.

Aprovado em: 27 de abril de 2018.

Publicado em: 21 de novembro de 2018. 